\title{
Physical Education Curriculum System Innovation Based on Students' Physical Health Test Result Management
}

\author{
Cuiqin Li \\ Hunan Vocational College of Modern Logistics, Changsha, Hunan, 410131
}

Keywords: statistical process control; quality management; application method

\begin{abstract}
The physical education curriculum teaching policy in China is based on the student's physical fitness and health, from the stipulation of the nature, form and connotation of the physical education curriculum, to the key point of opening and regulation, the concept of rights and obligations, and then to the standardized, modern development of the physical education curriculum. The relatively continuous series of administrative decisions in the teaching policy paradigm are characterized by significant changes in the political, economic and social environment in different periods. As far as the cause of the reform and development of the business is concerned, it is represented by the evolution from the administrative promotion to the system promotion. In the past ten years, with the adjustment and shift of the state's teaching policy on physical education curriculum, the construction of the physical education curriculum system has entered an active exploration stage, the most typical of which is the institutional adaptive adjustment and system construction based on resource development and utilization. The study believes that physical education is a specific school education activity and social cultural phenomenon based on physical activity and athletic ability. The key to the innovation of physical education curriculum system is to restructure the physical education curriculum teaching system framework by strengthening the main body of innovation to strengthen physical education research, to reduce the physical education system teaching system tension, to strengthen sports hardware construction as the basis for the establishment of physical education curriculum system platform, and to strengthen sports software development as a path to enrich the connotation of physical education curriculum system.
\end{abstract}

\section{Introduction}

Higher education should be innovative, and the innovation of education is essential. If the definition of innovation is defined as the successful production, absorption, and application of new things in science, economics, and social fields, and new methods of solving problems are provided to continuously meet the new needs of individuals and society, then the ontology innovation of higher education is the educator. Under the guidance of the new concept of education, concrete and creative educational activities will be constructed with new teaching relationships, educational content, and educational methods. Through active participation, active practice, and active exploration, educators will cultivate their sense of innovation and train their innovative thinking. Innovate and practice capabilities, improve the quality of personnel training, and then achieve educational innovation. Physical education is an integral part of the education of colleges and universities, and it is an indispensable link in the work of talent cultivation. The education ontology can be summed up in the three main aspects of educational ideology, teaching work and teaching system. To achieve innovation, education must be based on innovation. The ideological concepts are the core of the forerunner, the innovation of teaching work, and the innovation of the teaching system. The organic combination of the three is promoted as a whole, so that the proper function of college sports in cultivating high-quality talents can be fully realized [1].

\section{Construction of Physical Education Curriculum System}

To sum up, the first is the adjustment of course operation mode or organization mode. Including systematically guiding students to watch large-scale competitions such as the Olympics and World 
Championships; using unitary pedagogy to set up experimental classes to overcome the disadvantages of past teaching materials such as sporadic arrangements, lack of attention to match-ups, changes in venues and seasons, and teaching in combination with practical lessons to improve students The scientific training ability lays the foundation for lifelong sports. The survey of this study found that after one class of a school passed an ascent training, the number of students with a sense of tension decreased from $44.1 \%$ to $16.3 \%$. In addition, the use of modern technology teaching has also played an important role in institution building. The second is the change of teaching modes and learning methods. We have established a variety of teaching methods such as "being a small teacher", "freedom of play", "every lesson must be practiced", and "what I am a judge", as well as student small group activities and game competition. The third is the construction of a curriculum teaching evaluation system. The evaluation summed up, first, the adjustment of the course operating mode or organization [2]. Including systematically guiding students to watch large-scale competitions such as the Olympics and World Championships; using unitary pedagogy to set up experimental classes to overcome the disadvantages of past teaching materials such as sporadic arrangements, lack of attention to match-ups, changes in venues and seasons, and teaching in combination with practical lessons to improve students The scientific training ability lays the foundation for lifelong sports. The survey of this study found that after one class of a school passed an ascent training, the number of students with a sense of tension decreased from $44.1 \%$ to $16.3 \%$. In addition, the use of modern technology teaching has also played an important role in institution building. The second is the change of teaching modes and learning methods. We have established a variety of teaching methods such as "being a small teacher", "freedom of play", "every lesson must be practiced", and "what I am a judge", as well as student small group activities and game competition. The third is the construction of the course teaching evaluation system. The evaluation attaches great importance to and enhances the utilization rate of existing physical education resources in schools, and excavates and uses teaching resources for off-campus physical education courses (community public sports facilities and family environment), and seeks to change the sports scene in school physical education curriculum teaching, especially in light of resource conditions. The sports episode is a highlight of the changes in the school physical education teaching system in the past decade. Although the country had already requested that public stadiums should be further open to primary and middle school students as early as 1989, the institutionalization process was lagging behind and it was difficult to implement them at the school curriculum teaching system level. Comprehensive analysis, school and teachers in the past 10 years have deeper understanding of the new curriculum standards "health first" guiding ideology, physical education teachers believe that curriculum objectives meet the discipline characteristics of the curriculum and the students' age characteristics, reflecting the physical, psychological and social three-dimensional health idea. However, at present, most physical education teachers, especially rural primary school PE teachers, have not received any systematic education in sports and health knowledge, and do not have the ability to develop textbooks and select teaching content according to the "course standard". In addition, primary schools do not have physical education materials and require teachers. The good sports and health classes are quite reluctant. According to surveys, about one-third of the participants in the provincial-level backbone teacher training courses of the new curriculum standards are full-time coaches. They never participate in physical education, and nearly a third of the physical education teachers are mainly amateur trainers. Only one or two classes of physical education classes on the ground symbolically led to the tendency to have a younger, younger, or simpler copy of life scenes in the development of textbooks, or to change the original nature, characteristics, and value of textbooks, resulting in textbooks. The loss of multiple functions and values; in the preparation of teaching documents, it is vague and abstract. There are many problems in the setting of teaching goals, which are difficult to check and evaluate. Moreover, 53.5\% of school leaders still focus on school sports competitions, and do not place much emphasis on physical education and physical education curriculum reform; more than $90 \%$ of the city's primary and secondary sports venues are seriously deficient, and most rural primary and secondary school sports equipment are relatively lacking [3] This restricts the construction of the school physical 
education curriculum system.

\section{Innovation on Physical Education Curriculum System}

Sports are specific school education activities and socio-cultural phenomena based on physical activity and athletic ability. Judging from the existing research, there are roughly two views on sports. One is physical education as a medium and health as a goal; the other is education through physical activities that can be regarded as means and media. Obviously, there are four elements here: physical activity, visualization, health, and education. Among them, besides physical activity and education, health is an important disagreement between the two viewpoints, and the visual cannot be unified. In fact, from the training of physical activity to the training of athletic ability, the overall connotation and extension of sports are summarized. Whether it is regular sports, competitive sports, sunshine sports, entertainment sports, leisure sports, etc., its curriculum teaching is focused on or for physical activity and athletic ability. Based on this, the innovation of the school physical education curriculum system should be based on the inheritance and promotion of the institutional transformation, expansion and generation.

So far, the government and society have already reached consensus on enterprises as the main body of national science and technology and economic innovation, and schools have also begun to propose [4] as the main body of education innovation. The innovative subject of the school physical education curriculum teaching system is undoubtedly teachers and students, ie educators and educators, and implementers of the teaching process. The restructuring of the school physical education curriculum system framework is mainly to strengthen the participation, expression and decision-making rights of the innovation subject. The curriculum is the main line of instructional rights, and the government, schools, teachers, students, society as the pivot, teachers and students as the core. The function of the government is to formulate national education policies and policies, establish sports goals at different levels and types of schools, standardize the school sports system, and supervise school sports education. The school's function is to undertake the leadership of the physical education curriculum, formulate sports reform and development plans and implementation plans. The function of society is to provide convenience for the teaching of physical education courses and to supervise and evaluate the achievement of students' physical education teaching.

Strengthening education and scientific research is not only an important way to make educational decision-making scientific, but also an important "grip" for school-based physical education curriculum innovation. Judging from the sports programs and research projects of the National Education Science Program, the "Seventh Five-Year Plan" began to set up sports topics, including the "Comparative Study of School Sports" (Tian Jizong), but because there was no special sports and health subject group before the Ninth Five-Year Plan period, This topic is less concerned with the comparative analysis of social and economic backgrounds of Chinese and foreign school sports development. During the "Eighth Five-Year Plan" period, there were three sports topics: "China's School Sports Strategy Study in 2000" (Qu Zonghu), "Research on Deepening Physical Education Reform in Schools" (Li Jinyu) and "Experimental Study on Enhancing Students' Physique" (Tian Jizong), Sociological methods and intervention research methods were introduced [5]. The most typical of the "Ninth Five-Year Plan" was the compilation and experimental study of the new textbook "Sports and Health", and finally the experimental textbook of "Sports and Health" was formed. Since then, China's sports education research has entered a prosperous period. At present, the key to the scientific research of physical education in schools is the teacher's post teaching and research. At the institutional level, the focus is on solving problems such as the time and effort of the physical education teacher's teaching and research. In recent years, research on the implementation of sunshine sports, the implementation of lifelong sports, the teaching of physical education in the perspective of modern education, featured sports, women's sports, and the communication and convergence of physical education teaching at all levels of education may become systems. Breakthrough in innovation [5].

Physical education teachers are the hardware of school physical education curriculum, and the teacher training system belongs to the software category. At present, the first is to improve teachers 
through lectures. The sports class is a kind of purposeful and planned independent teaching link and teaching research activity in which the physical education teacher faces the "teaching" of a peer or an expert (judge) on certain occasions. At present, many school leaders and teachers are still unfamiliar with the connotation, content, and principles of sports lectures. This is related to people's attention, concepts, policies and regulations, and teaching evaluation. It is necessary to innovate in the teaching system of physical education courses in school social relations, relationship between teachers and students, and teacher-student relationship. The second is to train teachers in the development of sports school-based curriculum. The term "school-based curriculum" was put forward by Philip Lukmark et al. at the "School-based Curriculum Development Conference" held at the University of Ulster, Ireland, in 1973. The basic implication is that school teachers plan, design and implement the curriculum. At present, the development of sports school-based curriculum is not optimistic, especially the physical education teachers' curriculum awareness and individual ability do not meet the needs of the development of sports school-based curriculum. Reasonable selection, utilization and development of local sports education resources, full integration of sports traditions and sports programs of various nationalities and regions to develop sports school-based curriculum, establishment of sports school-based curriculum quality standards and evaluation systems, etc., will all become institutional innovations in school physical education curriculum. Space.

\section{Acknowledgements}

Fund Project: Hunan Provincial Department of Education Science Research Project (15C0964)

\section{References}

[1] Xu Hongwei. The Rationality of "Health" [J]. Journal of Beijing University of Physical Education, 2002, (6).

[2] Chen Qi. Reviewing the Reform and Development of School Physical Education in China from the Idea of Lifelong Physical Education[J]. Sports Science, 2004, (1).

[3] Zuo Qingsheng. School sports with independent character [J]. Sports Science, 2004, (6).

[4] Tang Jingping. On the process evaluation of physical education [J]. Anhui University of Technology Newspaper, 2005, (4).

[5] Shao Guihua. Combing and judging the objective theory of sports teaching in China [J]. SportsScience, 2005, (7). 